\title{
Universiteit
}

Leiden

The Netherlands

\section{The impact of early trauma and recent life-events on symptom severity in patients with conversion disorder}

\author{
Roelofs, K.; Spinhoven, P.; Sandijck, P.; Moene, F.; Hoogduin, C.A.L.
}

\section{Citation}

Roelofs, K., Spinhoven, P., Sandijck, P., Moene, F., \& Hoogduin, C. A. L. (2005). The impact of early trauma and recent life-events on symptom severity in patients with conversion disorder. Journal Of Nervous And Mental Disease, 193, 508-514. Retrieved from https://hdl.handle.net/1887/14283

Version: $\quad$ Not Applicable (or Unknown)

License: $\quad$ Leiden University Non-exclusive license

Downloaded from: $\quad$ https://hdl.handle.net/1887/14283

Note: To cite this publication please use the final published version (if applicable). 


\title{
The Impact of Early Trauma and Recent Life-Events on Symptom Severity in Patients With Conversion Disorder
}

\author{
Karin Roelofs, PhD, * Philip Spinhoven, PhD,* Pieter Sandijck, MA, † Franny C. Moene, PhD, $\dagger$ \\ and Kees A. L. Hoogduin, MD, PhD
}

\begin{abstract}
Although the presence of psychological stress factors in the evolution of conversion symptoms forms an important criterion for the DSM-IV diagnosis of conversion disorder, little is known about the nature and timing of these stress factors. Fifty-four patients with conversion disorder and 50 control patients with an affective disorder were screened for life events experienced in the year before the symptom onset. Conversion patients did not differ from control patients in the number or severity of life events, but showed a significant relation between the recent life events and the severity of conversion symptoms. Especially life events with respect to work and relationships contributed to this effect. These results remained when controlling for the previously found effects of childhood traumatization on the severity of conversion symptoms. The findings imply that conversion symptoms may be elicited by a complex of early and later negative life events and that traditional unifactorial trauma-theories of conversion disorder should be replaced by multifactorial stress models.
\end{abstract}

Key Words: Somatoform disorders, conversion hysteria, life events, childhood abuse, trauma.

(J Nerv Ment Dis 2005;193: 508-514)

U p to $20 \%$ of the patients attending specialist neurological clinics present symptoms that suggest neurological causes but, after examination, defy adequate medical explanation (Mace and Trimble, 1991). In many of these cases, psychological stress factors appear to be related to the symptoms, and a diagnosis of conversion disorder (DSM-IV) is applicable (American Psychiatric Association, 1994). Over $2 \%$ of the patients examined in neurological settings are

\footnotetext{
*Leiden University, The Netherlands; †De Grote Rivieren, Organization for Mental Health Care, Dordrecht, The Netherlands; and University of Nijmegen, The Netherlands.

Send reprint requests to Karin Roelofs, Section of Clinical and Health Psychology, Leiden University, P.O. Box 9555, 2300 RB Leiden, The Netherlands.

Copyright (C) 2005 by Lippincott Williams \& Wilkins

ISSN: 0022-3018/05/19308-0508
}

DOI: $10.1097 / 01 . n m d .0000172472 .60197 .4 \mathrm{~d}$ currently identified as suffering from conversion disorder (Binzer and Kullgren, 1998; Ron, 1994).

Although the relation between psychological stress factors on the one hand and the onset or exacerbation of conversion symptoms on the other hand forms a critical criterion for the DSM-IV (American Psychiatric Association, 1994) diagnosis of conversion disorder, little is known about the exact nature and timing of these psychological stress factors. Several authors have found conversion symptoms to be associated with early childhood traumatization (Alper et al., 1993; Betts and Boden, 1992; Bowman and Markand, 1996; Janet, 1907; Roelofs et al., 2002). Other authors stress the influence of emotional stress or conflict in the current life situation (American Psychiatric Association, 1994; Binzer et al., 1997; Irfan and Badar, 2002). These contradictions may be attributable to the fact that the studies reported so far followed a unifactorial approach, ignoring the possibility that the influence of early childhood traumatic events may interact with the impact of more recent life events.

Current neurobiological models of posttraumatic stress symptoms emphasize the influence of a combination of early and subsequent stressful events in predicting later onset psychopathology, and may be applicable to conversion disorder as well. There is a growing body of evidence in animals demonstrating that early adverse events, such as maternal deprivation, may have a long-lasting impact on neurobiological stress responses, involving chronic increases in plasma cortisol levels and a potentiation of glucocorticoid responsiveness to subsequent stressors (Anisman et al., 1998; Salpolski, 1997; Workel et al., 1997). In rats with a history of early parental deprivation, such increased glucocorticoid responsiveness was, for example, associated with increased freezing responses to subsequent stressors (e.g., Nunez et al., 1996). Also, in humans with a history of early traumatization, increased glucocorticoid stress responsiveness has been shown to be present in later age (Bremner et al., 1999). Moreover, in a sample of early traumatized patients with posttraumatic stress disorder, Cloitre et al. (1997) found that those patients who were exposed to a subsequent traumatic event showed increased dissociative and depressive symp- 
toms compared with patients who were not retraumatized. Similarly, Banyard et al. (2001) found victims of childhood sexual abuse who had experienced subsequent traumas to show more psychological distress in adulthood than victims of childhood abuse alone. These findings suggest that the combination of early traumatic events and later stressful life events in specific is predictive of the severity of psychopathology.

Although several controlled studies have shown a relationship between early traumatic childhood experiences and conversion symptoms (Alper et al., 1993; Betts and Boden, 1992; Bowman and Markand, 1996; Roelofs et al., 2002), there is only one controlled study available that focused on later stressful events that closely precede the onset of conversion symptoms. Binzer et al. (1997) found 30 patients with conversion symptoms who reported more negative life events during the year preceding the onset of the symptoms than 30 control patients with organic motor deficits. Unfortunately, no psychiatric control group was used, and it remains unknown whether there is a relation between the impact of certain stressful life events on the one hand and the severity of conversion symptoms on the other hand. To study this relation, it is necessary to conduct systematically controlled investigations of recent life events that precede the symptom onset in patients with conversion disorder. Most importantly, however, there is a need for studies addressing the possible role of recent life events as symptom-eliciting factors in the light of retraumatization in conversion patients with a history of childhood abuse. The latter question requires an investigation of both early and later occurring life events in patients with conversion disorder.

The purpose of the present study is twofold. First, it is investigated whether there are life events that are specifically related to the onset of conversion symptoms. To answer this question, patients with conversion disorder are compared with a control group of psychiatric patients with an affective disorder, with respect to life events experienced in the year preceding the symptom onset. Second, within the group of conversion patients, it is investigated whether there is a relation between certain life events and the severity of conversion symptoms. To examine the relative influence of recent life events and early childhood traumatization on conversion symptoms, previously published data on childhood traumatization and symptom severity in patients with conversion disorder (Roelofs et al., 2002) are related to the new data on recent life events that precede the symptom onset.

\section{METHODS}

\section{Patients}

A total of 58 patients diagnosed with conversion disorder was studied between 1997 and 2000. The patients had been referred for either inpatient or outpatient treatment to a general psychiatric hospital specializing in the treatment of conversion disorders. A psychiatrist assessed whether the patient met the DSM-IV criteria for conversion disorder (American Psychiatric Association, 1994). A trained psychologist checked for other Axis I diagnoses using the Structured Clinical Interview for DSM-IV Axis I Disorders (SCID-I/p; First et al., 1996b) and the Structured Clinical Interview for DSM-IV Dissociative Disorders (SCID-D; Steinberg, 1993). Axis II disorders were assessed using the Structured Clinical Interview for DSM-IV Axis II Personality Disorders (SCIDII; First et al., 1996a). A neurologist was responsible for the somatic screening, which was performed on all patients. Whenever the somatic screening revealed any deviations that might be related to the symptoms, the patients were excluded from the study.

Of the 58 conversion patients originally approached for participation in the present study, one patient was excluded because of illness, and three dropped out because of logistic reasons. A total of 45 women and nine men with conversion disorder were studied; their mean age was 37.6 years $(S D=$ 11.9). The incidence of motor conversion symptoms across patients was as follows: paralyzes/pareses $(N=38)$, coordination disorders $(N=26)$, tremors $(N=17)$, contractures $(N=12)$, bizarre movements $(N=12)$, speech disorders (aphonia and dysphonia; $N=13$ ), and eye muscle disorder $(N=5)$. As regards sensory symptoms, 19 of the patients had pain symptoms, 10 had disturbed feeling, and nine had a visual disorder. Pseudoepileptic seizures were observed in 17 patients. Note that the patients could be exhibiting more than one symptom. Of the 54 patients, 28 patients exhibited only motor symptoms, four had only pseudoepileptic seizures, three merely sensory symptoms, and 19 mixed symptoms. The mean period of sustained conversion complaints was 61 months $(S D=85)$.

As far as DSM-IV Axis I comorbidity is concerned, of the 54 conversion patients, 17 patients showed no other Axis I disorders (SCID-I, SCID-D). In the remaining 37, patients the following Axis I disorders were observed: mood disorder (21), panic disorder or agoraphobia (16), dissociative disorder (14), posttraumatic stress disorder (13), social or specific phobia (10), generalized anxiety disorder (2), bulimia nervosa (1), and obsessive compulsive disorder (1). With regard to Axis II diagnoses (SCID-II), 31 patients did not suffer from any personality disorder. In the remaining 23 patients, we observed the following types of personality disorder: avoidant (9), obsessive-compulsive (7), borderline (3), paranoid (3), antisocial (1), and dependent (1).

The comparison group consisted of 50 patients with one or more affective disorders. They had also applied for inpatient or outpatient treatment at either the aforementioned hospital or at an outpatient clinic specializing in the treatment of anxiety disorders. A psychiatrist made the diagnosis during 
the intake. For this purpose, the Münich Diagnostic Checklists for DSM-III-R and ICD-10 (Hiller et al., 1990) for mood and anxiety disorders were translated and adapted to the DSM-IV. The patients were matched to the sample of conversion patients on age and gender. A total of 41 women and nine men were included in the comparison group, and their mean age was 36.4 years $(S D=11.1)$. Twenty-five patients were diagnosed as suffering from a major depression, of which three were also afflicted by a panic disorder, two by a dysthymic disorder, one by a social phobia, and one by an eating disorder. Seven patients were exclusively affected by a panic disorder, six had social phobia, four generalized anxiety disorder, four dysthymic disorder, and three an adjustment disorder with mixed depression and anxiety. One patient had both a social phobia and a panic disorder.

All of the patients gave their informed consent before their participation.

\section{MATERIALS}

\section{Life Events}

All patients were presented with 48 life events of the VRMG (van de Willige et al., 1985) a Dutch self-report questionnaire addressing life events in the categories health/ illness/death (13 items), pregnancy/birth (six items), work (10 items), relationships (10 items), and other (nine items; for example, moving and significant changes in financial situation). For each event, patients indicated whether they had experienced an event in the 12 months preceding the symptom onset. For the positively answered events, patients moreover rated the pleasantness and the unpleasantness on two separate seven-item scales. For each category of life events as well as for the total of life events, two scores were calculated: the mean number of events and the mean impact rating. The latter was calculated by subtracting the unpleasantness score from the pleasantness score, with negative impact ratings reflecting a relative unpleasantness and positive impact ratings reflecting a relative pleasantness ascribed to the events. Since the impact ratings involve important information about the affective evaluation of the events, they were used as a major outcome measure.

\section{Childhood Traumatization}

The Structured Trauma Interview (STI; Draijer, 1989) addresses childhood experiences shown to be risk factors for adult psychopathology and includes parental dysfunction, parental physical abuse, and sexual abuse before age 16 (Draijer and Langeland, 1999). The expression parental refers to biological parents, stepparents, and adoptive parents. Parental dysfunction is a conceptualization of emotional neglect, referring to the unavailability of parents due to recurrent illness, nervousness, depression, alcohol misuse, or use of sedatives. Physical abuse was defined as severe pa- rental aggression including recurrent and chronic forms of physical violence frequently resulting in injuries, such as repeatedly being kicked or hit with a fist or an object (e.g., a stick or a belt), being tied up, or being thrown down the stairs. Sexual abuse was defined as any pressure to engage in or any forced sexual contact before age 16, originally ranging from fondling to penetration (Draijer and Langeland, 1999). In the present study, fondling only was not taken into account because it lacks a clear definition and its relation with adult psychopathology lacks evidence.

\section{Severity of Conversion Symptoms}

In the conversion group, the number of pseudoneurological symptoms (NOPS), with a maximum of 13, was assessed by the SCID-I (First et al., 1996b). Items are impaired coordination or balance, paralysis or localized weakness, difficulty swallowing, aphonia, urinary retention, loss of touch or pain sensation, double vision, hallucinations, blindness, deafness, seizures, amnesia, and loss of consciousness (not fainting).

Furthermore, self-reports of somatoform dissociative phenomena were measured using the 20-item Somatoform Dissociation Questionnaire (SDQ-20; Nijenhuis et al., 1996). Five-point scales are used to indicate to what degree presented statements apply. Statements include, "It sometimes happens to me that I grow stiff for a while," and, "It sometimes happens that it is as if my body, or part of it, has disappeared." The total score ranges from 20 to 100 . The reliability of the scale is high, and the construct validity is good (Nijenhuis et al., 1996).

\section{General Level of Psychopathology}

The general level of psychopathology was assessed by means of the Dutch version (Arrindell and Ettema, 1986) of the Symptom Checklist (SCL-90; Derogatis, 1983).

\section{Procedure}

After intake, one of two trained psychologists administered the SCID-I, the SCID-II, and the SCID-D in patients with conversion disorder. In control patients, diagnostic tools were administered during the intake. After the diagnostic procedures, a test psychologist administered the SCL-90, the SDQ-20, and the life event scale as part of a standard intake test protocol in all participants. To enable reliable administration of the life event scale, it was made sure that the participants had a clear view on the time episode of the year before the onset of the symptoms. To get clear markers of the target year, the participants were asked to recall any memories with respect to the start of the year, the subsequent seasons, and the end of the year before actual test administration took place. Within the course of the next 2 weeks, one of four trained psychologists, none of them involved in the initial assessment and all unaware of the clinical status of the patients, administered the STI. 


\section{RESULTS}

\section{Group Comparisons of Nonspecific Variables and Life Events}

Groups did not differ with respect to sex $\left(\chi^{2}[1]=.03\right.$; $p=0.86)$, age $(t[1,102]=.50 ; p=0.62)$, and level of education $(t[1,102]=1.83 ; p=0.07)$. The general level of psychopathology as measured by the total score of the SCL-90 was also equally high for patients with a conversion disorder $(M=201 ; S D=67)$ and patients with an affective disorder $(M=204 ; S D=60 ; t[1,102]=.26 ; p=0.80)$.

The mean number and the impact rating per category of life events experienced in the year preceding the symptom onset are presented in Table 1. $t$ Tests for independent samples showed no significant group differences for any of the variables (all $p$ values $>0.1$ ).

\section{Relationship Between Life Events and Symptom Severity}

To study the relationship between life events and symptom severity in patients with conversion disorder, regression analyses were conducted with the life events (total impact rating) as predictor and the NOPS and the SDQ-20 scores as dependent variables (in separated analyses). The life events predicted $14 \%\left(R^{2}=0.14 ; S E=2.22\right)$ of the variance for the NOPS $(\beta=-0.38 ; S E=.02 ; p<0.01)$ and $12 \%\left(R^{2}=0.12\right.$; $S E=7.83)$ for the SDQ-20 scores $(\beta=-0.35 ; S E=.07$; $p<0.01)$. For both NOPS and SDQ-20 scores counted, a greater negative impact rating (reflecting relative unpleasantness) was associated with a greater symptom severity. To find out whether specific categories of life events were related to the symptom severity, Pearson correlations were calculated between the impact ratings of the categories of life events and the NOPS and SDQ-20 scores, respectively. Work-related life events were significantly correlated with the NOPS $(r=$ $-0.37 ; p<0.005)$ and the SDQ-20 scores $(r=-0.38 ; p<$ 0.005 ), and life events with respect to relationships showed a significant correlation with the SDQ-20 scores $(r=-0.30$; $p<0.05)$ and a trend for the NOPS $(r=-0.24 ; p=0.08)$.
There were no such effects for health or pregnancy related life events (all $p$ values $>0.2$ ). To test the unique contribution of each category of life events, two separate regression analyses were conducted with all categories of life events entered simultaneously as predictors for the NOPS and SDQ-20 scores, respectively. Only work-related life events appeared to have unique predictive value. This counted for the NOPS $(\beta=-0.32 ; S E=.07 ; p<0.05)$ as well as for the SDQ-20 scores $(\beta=-0.34 ; S E=.24 ; p<0.05)$.

\section{Effect of Recent Life Events on Symptom Severity, Controlling for Childhood Abuse}

Previous regression analyses (Roelofs et al., 2002) showed that a history of childhood physical/sexual abuse significantly predicted $17 \%\left(R^{2}=.17 ; S E=2.17\right)$ of the variance for NOPS $(\beta=.41 ; S E=.59 ; p<0.005)$ and $7.5 \%$ $\left(R^{2}=.08 ; S E=7.99\right)$ of the variance for the SDQ-20 scores $(\beta=.28 ; S E=2.19 ; p<0.05)$ in the 54 conversion patients currently under study. The mean (SD) NOPS and SDQ-20 scores for the patients with a history of physical/sexual abuse $(N=24)$ were $6(2.3)$ and 33.21 (8.34), respectively, and those of patients without such history $(N=30)$ were 4.07 (2.05) and 28.70 (7.70), respectively. To find out whether the currently found effects for recent life events on NOPS remain significant after partialing out the previously found effects of childhood physical/sexual abuse, life events (total impact rating) and physical/sexual abuse were entered simultaneously into an additional regression analysis for NOPS. The findings showed that the effects of both life-events $(\beta=$ $-0.28 ; S E=.019 ; p<0.05)$ and of physical $/$ sexual abuse $(\beta=30.33 ; S E=.612 ; p<0.05)$ remained significant. The total model predicted $24 \%\left(R^{2}=.24 ; S E=2.11\right)$ of the variance of NOPS $(F[2,52]=7.79 ; p<0.001)$. As far as SDQ-20 scores are concerned, life events and physical/sexual abuse together predicted $16 \%\left(R^{2}=.16 ; S E=7.74 ; p<\right.$ $0.05)$ of the variance $(F[2,52]=4.84 ; p<0.05)$. Again, the effect of life events remained significant $(\beta=-.29 ; S E=$ $.071 ; p<0.05)$. The effects of early physical/sexual abuse

TABLE 1. Life Events Reported by Conversion Patients and Control Patients, Mean (SD)

\begin{tabular}{llcllc}
\hline & \multicolumn{2}{c}{ Conversion patients $(\boldsymbol{N}=\mathbf{5 4})$} & & \multicolumn{2}{c}{ Control patients $(\boldsymbol{N}=\mathbf{5 0})$} \\
\cline { 2 - 3 } Life events & $\begin{array}{c}\text { Mean } \\
\text { number }\end{array}$ & $\begin{array}{c}\text { Impact rating } \\
\text { (pleasant-unpleasant) }\end{array}$ & & $\begin{array}{c}\text { Mean } \\
\text { number }\end{array}$ & $\begin{array}{c}\text { Impact rating } \\
\text { (pleasant-unpleasant) }\end{array}$ \\
\hline Health/illness/death & $1.0(1.2)$ & $-4.2(5.5)$ & & $0.8(0.9)$ & $-3.3(4.5)$ \\
Work & $0.9(1.2)$ & $-2.2(4.9)$ & & $0.9(1.1)$ & $-2.6(4.0)$ \\
Relationships & $0.6(1.0)$ & $-1.3(5.4)$ & & $0.5(0.7)$ & $-1.5(3.8)$ \\
Birth/pregnancy & $0.2(0.6)$ & $0.7(2.6)$ & & $0.3(0.8)$ & $0.9(3.1)$ \\
Other & $1.6(1.7)$ & $-2.2(7.8)$ & & $1.4(2.0)$ & $-1.8(5.4)$ \\
Total & $4.2(3.8)$ & $-9.1(15.8)$ & & $3.8(3.1)$ & $-8.2(10.9)$ \\
\hline
\end{tabular}


$(\beta=.21 ; S E=2.24 ; p=0.14)$ were, however, no longer significant when partialing out the effects of recent life events. These findings suggest that the previously found relation between childhood physical/sexual abuse and the SDQ-20 scores may be partly mediated by the effects of subsequent life events. To test for mediation, the following four criteria (Baron and Kenny, 1986) should be met. Physical/sexual abuse predicts the SDQ-20 scores (dependent variable) (1) and the life events (mediator) (2). Furthermore, there must be a significant association between life events and SDQ scores, after controlling for physical/sexual abuse (3), and finally, the initial relation between physical/sexual abuse should no longer be significant after controlling for recent life events (4). Except for the second premise, all criteria were met by the analyses described. An additional regression analysis showed the second premise, the prediction of life events (dependent variable) by physical/sexual abuse, to be confirmed as well $(\beta=-.29 ; S E=4.21 ; p<0.05)$. These findings indeed suggest that the previously found relation between childhood physical/sexual abuse and somatoform dissociative experiences is partly mediated by the effects of subsequent life events.

\section{DISCUSSION}

The main purpose of the present study was to investigate whether there is a relation between certain life events and the onset and severity of conversion symptoms. Conversion patients did not differ from control patients with an affective disorder with respect to the number or impact of life events they had experienced in the year preceding the symptom onset. However, conversion patients did show a significant relation between the perceived unpleasantness and the number of life events on the one hand, and the severity of conversion symptoms on the other hand. Life events appeared to predict not only the number of conversion symptoms but also self-reports of somatoform dissociative symptoms in patients with conversion disorder. Especially life events with respect to work and relationships appeared to be associated with an increased symptom severity. Work-related life events involved loss of job (due to discharge, early retirement, psychological problems, physical illness of self or partner), significant changes (promotion or change in responsibilities), or start of severe conflict. Life events with respect to relationships involved marriage or divorce of self or children, start of severe conflict (with partner, children, family, or close friend), or sudden loss of close friendship. These findings suggest that the impact of social-occupational rather than physical health-related life events is related to the symptom severity in patients with conversion disorder.

In the second place, we found the relation between recently experienced life events and the number of conversion symptoms to hold after partialing out the effects of childhood physical/sexual abuse. Also, the predictive value of the model increased after adding recent life events to childhood physical/sexual abuse as predictors for the conversion symptoms. Both early childhood abuse and subsequent life events appeared to independently affect the number of conversion symptoms. The previously found relation between childhood physical/sexual abuse and self-reports of somatoform dissociative symptoms, however, disappeared after partialing out the effects of recent life events. These findings suggest that the direct influence of childhood abuse on conversion symptoms may be partially mediated by the impact of later-occurring negative life events. Consequently, traditional unifactorial stress models of conversion disorder, stressing the importance of either childhood abuse or current stress factors, appear to be inadequate and should be replaced by multifactorial stress models, such as those offered by current neurobiological stress theories, that emphasize the influence of a combination of early and subsequent stressful events in predicting later-onset psychopathology. Our findings, for example, fit in well with current stress theories of posttraumatic stress symptoms, suggesting that the influence of traumatic childhood experiences may be reflected in an increased stress responsiveness to subsequent stressors (e.g., Bremner et al., 1999). Both animal and human research has shown that early traumatic life events can result in prolonged changes in the biological stress responsiveness of the HPA-axis (Anisman et al., 1998; Bremner et al., 1999; Salpolski, 1997; Workel et al., 1997). Whether the impact of recent life events is associated with an increased biological stress responsiveness in early abused conversion patients should be further explored. At the moment, there are only indirect indications for altered HPA-axis functioning from a study by Rief et al. (1998), showing elevated basal levels of psychophysiological arousal and cortisol in patients with somatization syndrome compared with healthy control subjects. Also, using a dexamethasone suppression test, Tunca et al. (1996) found postdexamethasone cortisol levels to be significantly higher in 25 patients with conversion disorder compared with healthy controls, which is suggestive of impaired suppression of cortisol in conversion disorder. To our knowledge, there are no studies available addressing the glucocorticoid stress responsiveness of conversion patients after stress induction. Other factors that were previously found to explain increased psychological distress after exposure to negative life events in victims of childhood sexual assault are coping strategies (Herman, 1992) and dimensions of attachment (Romans et al., 1995; Wind and Silvern, 1994). Future studies are needed to determine whether changes in biological and behavioral stress responsiveness play a role in the relation between early and later negative life events on the one hand and conversion symptoms on the other hand.

To our knowledge, the present study was the first to examine systematically the relation between recent life events and symptom severity in patients with conversion disorder. It 
should be noted, however, that it has the methodological shortcoming of being a retrospective study. Consequently, memory bias could be present, both in the form of underreporting of trauma due to dissociative amnesia and in the form of overreporting. Because of the need for confidentiality, the life event and trauma reports were not checked with relatives or police reports. As a result, the validity of the life events and abuse reports cannot be ensured. Despite this drawback, underreporting due to dissociative amnesia is rather unlikely because the conversion sample was not featured by dissociative amnesia as assessed by means of the SCID-D. To minimize the risk of overreporting, we used a structured trauma interview. The interviewers were carefully trained to adhere strictly to the prescribed interview guidelines and to continue questioning until they received a concrete answer. They did not report any suspicion about the reliability of the patients' memories. Moreover, the study involved a controlled investigation in which the interviewers were blind to the clinical status of the patients. To enable reliable administration of the life event questionnaire, it was made sure that the participants had a clear view on the time episode of the year before the onset of the symptoms. To get clear markers of that specific year, the participants were asked to recall memories of the start, subsequent seasons, and the end of the year before test administration. We believe that these precautions have contributed to a maximal reliability and validity of the study.

In conclusion, the impact of life events experienced in the year preceding the symptom onset is positively related to the symptom severity in patients with conversion disorder. Especially life events with respect to work and relationships contributed to this result. The effects found for life events emerge on and above the previously found effects of childhood traumatic events on the severity of conversion symptoms. The present results suggest that a complex of lifetime stressors may play a part in conversion disorder and that traditional unifactorial trauma theories of conversion disorder should be replaced by multifactorial stress models. Future experimental studies are needed to investigate the behavioral and neurobiological stress responsiveness in patients with conversion disorder.

\section{ACKNOWLEDGMENTS}

The authors would like to thank Marieke van den Burgh, Elsbeth Nauta, and the staff members at De Grote Rivieren, Organization for Mental Health Care, Dordrecht, The Netherlands, for their assistance during data collection.

\section{REFERENCES}

Alper K, Devinsky O, Perrine K, Vazques B, Luciano D (1993) Nonepileptic seizures and childhood sexual and physical abuse. Neurology. 43:1950-1953. American Psychiatric Association (1994) Diagnostic and Statistical Manual of Mental Disorders (4th ed). Washington DC: American Psychiatric Association.

Anisman H, Zaharia MD, Meaney MJ, Merali Z (1998) Do early life events permanently alter behavioural and hormonal responses to stressors? Int $J$ Dev Neurosci. 16:149-164.

Arrindell WA, Ettema JHM (1986) SCL-90: Dutch Translation and Adaptation. Lisse: Swets \& Zeitlinger.

Banyard VL, Williams LM, Siegel JA (2001) The long-term mental health consequences of child sexual abuse: An exploratory study of the impact of multiple traumas in a sample of women. J Trauma Stress. 14:697-715.

Baron RM, Kenny DA (1986) The moderator-mediator variable distinction in social psychological research: Conceptual, strategic and statistical considerations. J Pers Soc Psychol. 51:1173-1182.

Betts T, Boden S (1992) Diagnosis, management and prognosis of a group of 128 patients with non-epileptic attack disorder, part II: Previous childhood sexual abuse in the etiology of these disorders. Seizure. 1:27-32.

Binzer M, Andersen PM, Kullgren G (1997) Clinical characteristics of patients with motor disability due to conversion disorder: A prospective control group study. J Neurol Neurosurg Psychiatr. 63:63-68.

Binzer M, Kullgren G (1998) Motor conversion disorder: a prospective 2- to 5-year follow-up study. Psychosomatics. 39:519-527.

Bowman ES, Markand ON (1996) Psychodynamics and psychiatric diagnoses of pseudoseizure subjects. Am J Psychiatry. 153:57-63.

Bremner JD, Narayan M, Staib LH, Southwick SM, McGlashan T, Charney DS (1999) Neural correlates of memories of childhood sexual abuse in woman with and without posttraumatic stress disorder. Am J Psychiatry. 156:1787-1795.

Cloitre M, Scarvalone P, Difede J (1997) Posttraumatic stress disorder, selfand interpersonal dysfunction among sexually retraumatized women. J Trauma Stress. 10:437-452.

Derogatis LR (1983) Symptom Checklist-90-R: Administration, Scoring and Procedures Manual. Baltimore (MD): Clinical Psychometric Research.

Draijer N (1989) Structured Trauma Interview. Vrije Universiteit Amsterdam: Department of Psychiatry.

Draijer N, Langeland W (1999) Childhood trauma and perceived parental dysfunction in the etiology of dissociative symptoms in psychiatric inpatients. Am J Psychiatry. 156:379-385.

First MB, Gibbon M, Spitzer RL, Williams JBW, Benjamin LS (1996a) Structured Clinical Interview for DSM-IV Axis II Personality Disorders (Version 2.0). New York: Biometrics Research.

First MB, Spitzer RL, Gibbon M, Williams JBW (1996b) Structured Clinical Interview for DSM-IV Axis I Disorders (Version 2.0). New York: Biometrics Research.

Herman J (1992) Trauma and Recovery. New York: Basic Books.

Hiller W, Zaudig M, Mombour W (1990) Münich Diagnostic Checklists for DSM-II-R and ICD-10. München: Logomed.

Irfan N, Badar A (2002) Top ten stressors in the hysterical subjects of Peshawar. J Ayub Med Coll Abbottabad. 14:1-4

Janet P (1907) The Major Symptoms of Hysteria. New York: Macmillan.

Mace CJ, Trimble MR (1991) "Hysteria," "functional" or "psychogenic"? A survey of British neurologists' opinion. J R Soc Med. 84:471-475.

Nijenhuis E, Spinhoven P, Van Dyck R, Van der Hart O, Vanderlinden J (1996) The development and psychometric characteristics of the somatoform dissociation questionnaire (SDQ-20). J Nerv Ment Dis. 184:688694.

Nunez JF, Ferre P, Escorihuela RM, Tobena A, Fernandez-Teruel A (1996) Effects of postnatal handling of rats on emotional, HPA-axis and prolactin reactivity to novelty and conflict. Phys Behav. 60:1355-1359.

Rief W, Shaw R, Fichter MM (1998) Elevated levels of psychophysiological arousal and cortisol in patients with somatization syndrome. Psychosom Med. 60:198-203.

Roelofs K, Keijsers GPJ, Hoogduin CAL, Näring GWB, Moene FC, Sandijck P (2002) Childhood abuse in conversion disorder. Am J Psychol. 159:1908-1913.

Romans SE, Martin JL, Anderson JC, O'Shea ML, Mullen PE (1995) Factors 
that mediate between childhood sexual abuse and adult psychological outcome. Psychol Med. 25:127-142.

Ron MA (1994) Somatisation in neurological practice. J Neurol Neurosurg Psychiatry. 57:1161-1164.

Salpolski RM (1997) The importance of a well-groomed child. Science. 277:1620-1621.

Steinberg M (1993) Structured Clinical Interview for DSM-IV Dissociative Disorders (SCID-D). Washington DC: American Psychiatric Press.

Tunca Z, Fidaner H, Cimilli C, Kaya N, Biber B, Sena Y, Ozerdem A (1996)
Is conversion disorder biologically related with depression? A DST study. Biol Psychiatry. 39:216-219.

Willige van de G, Schreurs PJG, Tellegen B, Zwart F (1985) Vragenlijst recent meegemaakte gebeurtenissen. Ned Tijds Psych. 40:1-19.

Wind TW, Silvern L (1994) Parenting and family stress as mediators of the long-term effects of child abuse. Child Abuse Neglect. 18:439-453.

Workel JO, Oitzl MS, Ledeboer A, De Kloet ER (1997) The Brown Norway rat displays enhanced stress-induced ACTH reactivity at day 18 after 24-h maternal deprivation at day 3. Dev Brain Res. 12:199-203. 